\title{
Pre-Service Teachers attitudes and knowledge concerning Sexual Health Education in the field of Special Education
}

\author{
Yifat Gerchenovitch \& Alina S. Rusu
}




\title{
Pre-Service Teachers attitudes and knowledge concerning Sexual Health Education in the field of Special Education
}

\author{
Yifat Gerchenovitch ${ }^{a, c^{*}}$, Alina S. Rusu ${ }^{a, b}$ \\ ${ }^{a}$ Doctoral School "Education, Reflection, Development", Babes-Bolyai University, 7 Sindicatelor Street, Cluj-Napoca, 400029, Romania \\ ${ }^{b}$ Department of Special Education, Faculty of Psychology and Educational Sciences, Babeș-Bolyai University, 7 Sindicatelor Street, Cluj-Napoca, \\ 400029, Romania \\ ${ }^{c}$ Instructor in the field of Sexual Health Education in Special Education Department, Ministry of Education, Israel
}

*Corresponding author: yifatfish@gmail.com

Abstract

Keywords:

Sexual Health

Education, Special

Needs, knowledge, attitudes, sexuality and disability.
The objective of this study was to investigate the impact on knowledge and attitudes to sexuality, as well as the capability to teach sexual education topics, of a Sexual Health Education training program designed for pre-service teachers in the field of Special Education in Israel. The findings from the pre/ post investigation and the comparison with the control group (i.e. pre-service teachers that did not participate in the SHE training program) highlighted the impact of the background variables such as religiosity, age and marital status on the knowledge of SHE topics and attitudes towards sexuality and disability. Also, the findings indicate that there is a pervasive lack of knowledge of SHE in relation to persons with special needs among the pre-service teachers in Special Education in Israel. As knowledge and attitudes toward sexuality and disability vary between demographic groups, it is recommended that SHE training courses to be tailored to the participants needs, as well as to enable discussions and reflection on the challenges they may encounter.

\section{Zusammenfasung}

Schlüsselworte:

Sexuelle

Gesundheitserziehung, besondere

Bedürfnisse, Wissen,

Einstellungen,

Sexualität und

Behinderung.
Ziel dieser Studie war es, die Auswirkungen auf das Wissen und die Einstellung zur Sexualität sowie die Fähigkeit, Themen der Sexualerziehung zu vermitteln, eines Trainingsprogramm zur sexuellen Gesundheitserziehung (SGE), das für werdende Lehrer im Bereich der Sonderpädagogik in Israel konzipiert wurde. Die Ergebnisse aus der Vor- $/$ Nachuntersuchung und dem Vergleich mit der Kontrollgruppe (d.h. werdende Lehrkräfte, die nicht am SGESchulungsprogramm teilgenommen haben) haben die Auswirkung der Hintergrundvariablen wie Religiosität, Alter und Familienstand auf das Wissen über SGE Themen und Einstellungen zu Sexualität und Behinderung, hervorgehoben. Die Ergebnisse deuten auch darauf hin, dass es unter den werdenden Lehrkräften für Sonderpädagogik in Israel einen allgegenwärtigen Mangel an Kenntnissen über SGE in Bezug auf Personen mit besonderen Bedürfnissen gibt. Da das Wissen und die Einstellungen zu Sexualität und Behinderung zwischen den Bevölkerungsgruppen unterschiedlich sind, wird empfohlen, SGU-Schulungen auf die Bedürfnisse der Teilnehmer abzustimmen und Diskussionen und Überlegungen zu den möglichen Herausforderungen zu ermöglichen.

\section{Introduction}

Several recent studies indicate the importance of training programs for teachers intending to deliver Sexual Health Education (SHE) in mainstream schools (Arrington et al., 2018; Leung et al., 2019; McKay \& Barrett, 1999) and in the field of Special Education (Owens, 2014; Thorpe \& Oakes, 2019; Treacy et al., 2018). The lack of insufficient preparation of teachers for delivering SHE in Special Education (SE) has been reported as one of the obstacles preventing effective SHE for young people with special needs (Attwood, Henault, \& Dubin, 2014; Goldman \& Coleman, 2013; Klein \& Breck, 2010; May \& Kundert, 1996; Wilkenfeld \& Ballan, 2011; Travers et al., 2014). Among other factors, the perceptions of the sexual identity of people with disabilities may hamper teacher's delivery of SHE to students in SE (Swango-Wilson, 2010; Parchomiuk, 2013).

It has been found that the beliefs and cognitions of preservice teachers (PSTs), as well as their knowledge and technical skills, can negatively impact not only what they teach when delivering SHE, but also their self-perceived teaching efficacy (Barnard-Brak et al., 2014; HowardBarr et al., 2005; Thorpe \& Oakes, 2019). Teachers also report as having inadequate training for teaching SHE (Arrington et al., 2018; Eisenberg et al., 2010). It is therefore critically important that SHE training programs should be offered to PSTs, and that, besides the competencies-based learning outcomes, these training 
programs should also be assessed for their psycho-social effects (knowledge, attitudes, readiness to teach SHE) on the trainees.

Cultural backgrounds and religious beliefs have been shown to affect PSTs pre-existing knowledge, training and perceptions regarding SHE in general and in SE (Lapidot Berman \& Firstater, 2018). It is therefore important that these factors be assessed in groups undergoing SHE training so that the course can be adapted accordingly, as it is possible that different levels of training will be needed amongst different demographic groups.

\section{Theoretical foundation}

SHE training programs are rooted in several models and approaches, such as: the cognitive theory (e.g. Lewin, 1951), the trans theoretical model (Prochaska et al., 1994), the health belief model (Abraham \& Sheeran, 2005; Rosenstock, 1991), and health behaviour theory (Bronfenbrenner \& Morris, 2007). Updated versions of these theories and models include an emphasis on selfefficacy, expectations, cues to action and demographic and socio-economic variables regarding the trainees (Taylor et al., 2007). SHE programs that are grounded in evidence-based theories and subjected to assessments of their outcomes appear to be more successful in meeting their goals (Haberland \& Rogow, 2015). The attitudes of teachers about SHE, their knowledge on SHE topics and their willingness to teach SHE in special education can impact the success of SHE programs in SE (Argaman, 2018; Cozzens, 2006; Foley, 2008; Iyer \& Aggleton, 2013; Peltzer \& Promtussananon, 2003).

While some SHE programs in SE have been recently developed in Israel (Lachover \& Argaman, 2007; ManorBinyamini, Schreiber-Divon \& Stein, 2013), there have not yet been sufficient studies of the impact of these programs on the teachers' attitudes and knowledge in relation to SHE for persons with special needs (Gerchenovitch \& Rusu, 2018). One study was carried out in Israel investigating the effect of a program preparing the teachers to conduct SHE in a SE school (ManorBinyamini et al., 2013), but this program focused mainly on the prevention of sexual harassment. A systematic literature review conducted by Schaafsma et al. (2015) on the preparation of teachers to deliver SHE for individuals with intellectual disabilities found that theoretical knowledge was not always translated into practice. Furthermore, clear methodologies for assessing the outcomes of the SHE training programs were lacking (Schaafsma et al., 2017).

Based on the results of a literature systematic review aiming to identify the components of SHE curricula in the field of Special Education (Gerchenovitch \& Rusu, 2018), a new SHE curriculum was formulated by the authors, together with other experts in the field of SE in Israel. This curriculum was delivered by the researcher (YG) and other three lecturers to pre-service teachers in SE at four colleges in Israel, during the 2017-2018 academic year (language of teaching: Hebrew). The main aspects of the SHE training program for pre-service teachers are presented below.

The SHE training program was designed to familiarize students with the various stages of sexual development, along with the understanding of the implication of disability in social and cultural contexts as well as on the individual's identity. The program also aims to teach ways of coping with real-life situations and dilemmas pertaining to sexuality, using professional tools to promote a discourse on subjects related to adolescence and sexuality among the SE population, while referring to specific characteristics of age and disability. The course goals are the following: (1). Cultivating positive attitudes to human sexuality in general and sexuality of persons with disability in particular; (2). Instilling basic knowledge of sexual development and behaviour of children and youths with and without developmental disabilities; (3). Raising awareness to situations of sexual risk, exploitation, and abuse; (4). Defining the role of the educational staff in relation to the students' maladjusted sexual-social behaviours; (5). Development of ways to cope with various situations that may arise in daily school life.

In terms of outcomes, students are expected to be able to accomplish the following at the end of the course: detect and respond professionally to inappropriate sexual behaviour in the classroom and the school, conduct a discussion with the students on topics related to sexuality education, and integrate topics related to sexuality education in the personal and class curriculum. The SHE training program consisted of 15 ninety-minute lessons, with each lesson dedicated to a specific topic including: The concept of sexuality; attitudes to human sexuality; Human sexuality and disabilities: clarifying attitudes and sexual rights; Sexuality education: the PLISSIT model; Psycho-sexual development and education; 
Characteristics of psycho-sexual development of students with special needs; Privacy and personal space; Social distances; The continuum of sexual behaviour; Sexual assault/abuse; The influence of the media on sexual development and behaviour; Addiction to sex; Detecting and identifying risk situations in the sexual-social realm; Discussing sexuality with parents.

The objective of the study was to quantitatively assess the impact of participating in an SHE training program for PST intending to teach in SE on knowledge, attitudes and capability of SE PST in relation to SHE training. The following hypotheses were formulated:

- Hypothesis 1. Following the participation in the SHE training, there will be an increase in knowledge of the PSTs from the experimental group on topics related to sexual health and to sexual health and disability, in comparison to the control group.

- Hypothesis 2. Following the participation in the SHE training, the PSTs' attitudes towards sexual health and disability in the experimental group will be more favourable as compared to the pretest condition.

- Hypothesis 3. Following the participation in the SHE training, there will be an increase in the PSTs' capability to teach SHE in SE as compared to the pre-test condition.

\section{Research Methodology}

\section{Participants}

Participants to this study were 179 Israeli SE preservice teachers, who attended colleges and teaching seminars during academic year 2017-2018. All the participants were native Israelis, with Jewish religion orientation. The experimental group included 128 students who intended to take part in an SHE training course later on in the academic year. The control group included 51 students, who were not intending to take part in this course. Overall, in the study participated 170 females (ages between 24 and 37; $M=28.11, S D=4.14$ ) and 9 males (ages 20 and 57, $M=27.02, S D=6.95$ ). No significant difference was found between the age range of males and females, $t(177)=.47, p=.638$. Due to the wide range in age among the males sample, we examine whether differences were found in the variance of the participant's age by gender, using Leven's test for equality of variance. No significant difference was found in the variance of age by gender $(F=1.49, p=.224)$

\section{Instruments}

A package of questionnaires, i.e. KASHED (Knowledge and Attitudes to SHE and Disability), was individually distributed to the PSTs prior and after the SHE training program. The questionnaires consisted of six sections, as it follows: Section A included 11 demographic questions; section $\mathrm{B}$ included 4 questions relating to the participant's experience of SHE in adolescence; Section $C$ included 11 questions addressing the current views on SHE in SE; section D included 17 questions related to knowledge of SHE topics, such as: anatomy and physiology of reproductive organs, abortions, sexual orientations and sexual violence; section E included 12 statements relating to attitudes about sexuality for people with disabilities which the PSTs were asked to score from 1-4 according to their level of agreement with the statements and finally section $F$ included 16 statements about attitudes towards sexuality which the PSTs were asked to score from 1-5 according to their level of agreement with the statements. The KASHED package of questionnaires were assembled and adapted for usage in Hebrew language from the following validated questionnaires:

- Brosch's Questionnaire that assesses the Attitudes, Knowledge, and Willingness of Preservice teachers of Education to deal with topics connected to Sex and Family Life Education as part of their teaching tasks (Brosch, 2007).

- Reuth Open Door - IFPA's (Israel Family Planning Association) Questionnaire: Attitudes about Sexuality for People with Disabilities (Porat, 2009).

- Attitudes toward Sexuality Scale (ATSS), Fisher, Davis, Yarber, \& Davis (1988).

\section{Results}

No significant differences were found between the attitudes towards and knowledge of SHE topics in general 
and SHE in SE in particular between the male and female participants in the study. There was a smaller change in knowledge and attitudes to sexuality between before and after the SHE training program amongst those participants who were already working in the SE sector than amongst the participants who were full time students. Before the SHE training, the participants who were married or in a relationship had significantly more positive attitudes towards sexuality and sexuality and disability compared to those that were single. However, whether the students had children or not, did not have an impact either upon knowledge and attitudes to sexuality and disability before the course, neither after the course.

Before the SHE training, significantly lower levels of knowledge on SHE topics were found amongst participants defining themselves as being religiously observant, than amongst those defining themselves as either traditional or secular. The attitudes about sexuality were also found to be more negative among those defining themselves as religiously observant before the SHE training. There was a significant increase in knowledge of SHE topics amongst the religiously observant students after the training, compared to those that were not defining themselves as religiously observant.
A positive correlation was found between the level of sexual knowledge and the attitudes towards sexuality and the age of the participants, $r(177)=.41, p=.000$ and $r(177)=.25, p=.001$, respectively), indicating that as the age of the participant increases, the level of sexual knowledge is higher and that there are more positive attitudes towards sexuality. No significant correlations were found between the parents' education and the year of the participant's college studies and levels of knowledge of SHE topics or attitudes to sexuality or to sexuality and disability.

Three multiple regression analyses were conducted in order to examine the contribution of the PST's background characteristics to their level of knowledge on topics related to SHE, the attitudes towards sexuality and disability and the attitudes towards sexuality before the SHE training. Three additional regression analyses were conducted in order to examine the contribution of the PST's background characteristic and the grouping variable to the level of knowledge on topics related to SHE, the attitudes towards sexuality and disability and the attitudes towards sexuality after the SHE training. The independent variables were entered in a stepwise manner. The only variables that contributed significantly to the explained variance were entered into the equation.

Table no. 1. Results of multiple regressions for the knowledge in topics related to SHE, the attitudes towards sexuality and disability and the attitudes towards sexuality in relation to the background characteristics of the PST before the SHE training

\begin{tabular}{|c|c|c|c|c|c|c|c|c|}
\hline $\begin{array}{l}\text { Dependent } \\
\text { variables }\end{array}$ & Steps & $\begin{array}{l}\text { Independent } \\
\text { variables }\end{array}$ & $\boldsymbol{B}$ & $S E . B$ & $\boldsymbol{\beta}$ & $t$ & $R^{2}$ & $\Delta R^{2}$ \\
\hline $\begin{array}{l}\text { Level of } \\
\text { knowledge }\end{array}$ & 1 & Religious & -1.36 & .24 & -.41 & $\stackrel{-}{-}$ & $.172 * * *$ & $.172 * * *$ \\
\hline $\begin{array}{l}\text { Attitudes to } \\
\text { sexuality and } \\
\text { disability }\end{array}$ & 1 & Marital status & .19 & .07 & .21 & $2.66^{* *}$ & $.044 * *$ & $.044 * *$ \\
\hline \multirow{10}{*}{$\begin{array}{l}\text { Attitudes } \\
\text { towards } \\
\text { sexuality }\end{array}$} & 1 & Religious & -.37 & .05 & -.52 & $\begin{array}{c}- \\
7.66^{* * * *}\end{array}$ & $.275^{* * *}$ & $.275^{* * *}$ \\
\hline & 2 & Religious & -.33 & .05 & -.47 & 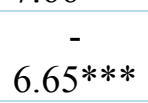 & & \\
\hline & & Age & .01 & .01 & .16 & $2.25^{*}$ & $.298 * * *$ & $.023^{*}$ \\
\hline & 3 & Religious & -.29 & .05 & -.41 & - & & \\
\hline & & Age & .03 & .01 & .30 & $3.19 * *$ & & \\
\hline & & Children & -.28 & .13 & -.20 & $-2.24 *$ & $.320 * * *$ & $.022 *$ \\
\hline & 4 & Religious & -.29 & .05 & -.41 & $\stackrel{-}{-}$ & & \\
\hline & & Age & .03 & .01 & .29 & $3.13 * *$ & & \\
\hline & & Children & -.42 & .14 & -.29 & $-2.94 * *$ & & \\
\hline & & Marital status & .21 & .11 & .17 & $2.01 *$ & $.338 * * *$ & $.018^{*}$ \\
\hline
\end{tabular}


The level of self-perceived religiousness (or religiosity) contributed significantly to the explained variance (EPV) of the knowledge on topics related to SHE and the attitudes towards sexuality before the SHE training (17.2\% and $27.5 \%$, respectively, table no. 2$)$. The negative $\beta$ coefficient indicated that the knowledge on topics related to sexual education was greater and the attitudes towards sexuality were more positive among secular PSTs compared to religious PSTs at this time point.

The marital status contributed significantly to the EPV of the attitudes towards sexuality and disability and the attitudes towards sexuality before the SHE training.
The positive $\beta$ coefficient indicated that the attitudes towards sexuality and disability and the attitudes towards sexuality were more positive among married PSTs or those with a stable partner compared to single or divorced PSTs.

The age of the PSTs contributed significantly to the EPV of the attitudes towards sexuality before the intervention with a positive $\beta$ coefficient, indicating that as the age increases, the attitudes towards sexuality become more positive. Finally, the negative $\beta$ coefficient of the "children" variable indicated that PSTs without children had a more positive attitude towards sexuality compared to PSTs with children.

Table no. 2. Results of multiple regressions for knowledge of topics related to SHE, the attitudes towards sexuality and disability and the attitudes towards sexuality in relation to the background characteristics of the PSTs after the SHE training

\begin{tabular}{|c|c|c|c|c|c|c|c|c|}
\hline $\begin{array}{l}\text { Dependent } \\
\text { variables }\end{array}$ & Steps & $\begin{array}{l}\text { Independent } \\
\text { variables }\end{array}$ & $\boldsymbol{B}$ & $S E . B$ & $\beta$ & $t$ & $R^{2}$ & $\Delta \boldsymbol{R}^{2}$ \\
\hline $\begin{array}{l}\text { Sexual } \\
\text { knowledge }\end{array}$ & 1 & Group & 2.11 & .42 & .37 & $5.03 * * *$ & $.140 * * *$ & $.140 * * *$ \\
\hline \multirow{3}{*}{$\begin{array}{l}\text { Attitudes to } \\
\text { sexuality } \\
\text { and } \\
\text { disability }\end{array}$} & 1 & Group & .57 & .07 & .53 & $7.81 * * *$ & $.283 * * *$ & $.283^{* * *}$ \\
\hline & 2 & Group & .55 & .07 & .51 & $7.50 * * *$ & & \\
\hline & & Marital status & .13 & .06 & .14 & $1.99 *$ & $.301 * * *$ & $.018 *$ \\
\hline \multirow{3}{*}{$\begin{array}{l}\text { Attitudes } \\
\text { towards } \\
\text { sexuality }\end{array}$} & 1 & Religious & -.28 & .05 & -.40 & $\begin{array}{c}- \\
5.43 * * *\end{array}$ & $.160 * * *$ & $.160 * * *$ \\
\hline & 2 & Religious & -.27 & .05 & -.38 & $\begin{array}{c}- \\
5.44 * * *\end{array}$ & & \\
\hline & & Group & .47 & .10 & .32 & $4.58 * * *$ & $.261 * * *$ & $.101 * * *$ \\
\hline
\end{tabular}

Participation in the SHE training program (the experimental group) had a significant effect on the knowledge of SHE topics of the PSTs from all the different backgrounds (table no. 3). Furthermore, the positive $\beta$ coefficient indicates that amongst the PSTs who had participated in the course (experiment group) the knowledge on topics related to SHE was greater amongst secular PSTs than amongst the religious PSTs. Likewise, attitudes towards sexuality and disability and the attitudes towards sexuality were more positive among secular PSTs who had been enrolled in the SHE training program compared to PSTs who did not enrol in the SHE training program.

Compared to the results of the regression analyses before the SHE training, the marital status of the PTSs significantly contributed to the EPV of the attitudes towards sexuality and disability. The positive $\beta$ coefficient indicated that the attitudes towards sexuality and disability after participating in the SHE training program were more favourable among married PSTs or those with a stable partner as compared to single or divorced PSTs. 
Moreover, compared to the results of the regression analyses before the course had been delivered, the level of self-perceived religiousness of the PSTs significantly contributed to the EPV of the attitudes towards sexuality. The negative $\beta$ coefficient indicated that the attitudes towards sexuality were more favourable among secular PST's compared to religious PST's after the SHE training program. The experimental group was found to have significantly higher levels of knowledge of SHE topics after participating in the SHE training $(M=9.11, S D=$ 2.19 ) in the experimental group than the control group ( $M$ $=7.18, S D=3.00), t(177)=4.78, p<.000$. Participation in the training course also impacted upon the attitudes of the PSTs to a wide variety of issues including whether people with a disability have the same sexual needs as those without a disability; whether everyone has the right to exercise his or her sexual potential regardless of their physical or mental condition; whether people with a disability have the same libido as those without a disability; whether people with a disability should have more important issues to see to than sexual relations and finally whether sex is good only if you can "go all the way".

\section{Discussions}

The research findings show that the Israeli pre-service teachers who participated in the SHE training course increased their knowledge in topics related to SHE in general and SHE in Special Education in particular. These findings support the literature indicating that training courses preparing teachers to deliver SHE in SE are needed (Daciuk, 2015; Lapidot-Berman \& Firstater, 2018). They also show that certain background characteristics, such as gender and religious observance, may influence the knowledge of topics related to SHE, as well as the level of favourability of the attitudes to sexuality and to sexuality and disability. The results matched other studies that showed that levels of religiosity could impact the attitudes and knowledge related to SHE in Special Education (Apteslis, 2019; Sheridan, 2016).

The innovative curricula of this SHE course was associated with several positive outcomes on the Israeli PSTs who participated in the course, such as increase in their knowledge in topics related to SHE in general and SHE in the SE population and increase in the level of favourable attitudes to SHE in general and SHE in SE in particular. The most significant change in attitudes after participating in the SHE course was related to the age from which SHE should be taught. After participating in the SHE training program, the majority of PSTs thought that SHE should start at early stages of development, such as kindergarten. Also, the majority of PSTs who participated in the SHE training program (around 80\%) indicated that they feel willing and capable to teach SHE to special needs persons.

In terms of identified limits, although the study was conducted in four different teacher-training colleges in Israel, the population of the current study included only Jewish students. It is hoped that future studies will include a more diverse population. Israel is a multicultural country and a study population including ethnic minorities and recent immigrants could have made an interesting study. More diverse samples may yield other important findings relating to cultural and other important variables. Further research can also explore, as part of the demographic background, whether the teachers had friends or family members with disabilities and how this affects their attitudes and capability to teach SHE in the field of Special Education.

\section{Conclusions}

The fact that knowledge and attitudes toward sexuality and sexuality and disability were changed significantly by the participation in the Sexual Health Education training program in Special Education, on the one hand underlined the prevalent lack of knowledge and less favourable attitudes to sexuality of people with disabilities, but on the other hand supported the idea that participation in a specially designed training course can significantly change in a positive direction the levels of preparedness of pre-service teachers to teach Sexual Health Education for special needs students.

\section{Authors note:}

The authors have equal contributions to this article.

Yifat Gerchenovitch is the national coordinator of Sexual Health Education in the Special Education Department, Ministry of Education, Israel. She is currently a PhD student at Babeş-Bolyai Cluj-Napoca, in Romania. Her research is directed towards promoting sexual health education within the special education sector, with the aim of improving students' quality of life including their basic human right of healthy sexuality. 
Alina S. Rusu (biologist and psychologist) is currently an Associate Professor in the Department of Special Education, School of Psychology and Educational Sciences, Babes-Bolyai University, Cluj-Napoca, Romania and member of the Doctoral School "Education, Reflection, Development" (domain: Psychology). Her professional and research interests are: humane education, interdisciplinary curriculum development, applied values of human-animal interactions and the multidimensional study of community-oriented volunteering. She teaches courses in animal psychology, psychobiology of human sexuality, and positive psychology applied to inclusive institutions.

\section{References}

Abraham, C., \& Sheeran, P. (2005). The Health Belief Model. In Connor M. \& Norman, P. Eds. Predicting Health Behaviour. Maidenhead: Open University Press.

Apteslis, N. (2019). The View on the Sexual Education of People with Autism in Modern Greek Society. Journal of Autism, 6(2), 1-6.

Argaman, R. (2018). Sex and Sexuality in People with Intellectual Developmental Disabilities. Shikum - Journal of Rehabilitative Social Workers in Israel, 38-47.

Arrington, A.B., Ismail, O.H., Werle, N., Esters, J., Frederick, S., Ellis, K., \& Kolbo, J. R. (2018). Sex-Related Education: Teacher Preparation and Implementation. National Teacher Education Journal, 11(1), 5-14.

Attwood, T., Henault, I., \& Dubin, N. (2014). The autism spectrum, sexuality and the law: What every parent and professional needs to know. Jessica Kingsley Publishers.

Barnard-Brak, L., Schmidt, M., Chesnut, S., Wei, T., \& Richman, D. (2014). Predictors of access to sex education for children with intellectual disabilities in public schools. Intellectual and Developmental Disabilities, 52(2), 85-97.

Bronfenbrenner, U. \& Morris, P.A. (2007). The Bioecological Model of Human Development in: Handbook of Child Psychology. New York: John Wiley \& Sons.

Brosch, I. (2007). Awareness, knowledge, and willingness to deal with sexual education among student teachers: Research report. Tel Aviv: Mofet. (Hebrew).

Cozzens, J. (2006). Assessing the awareness of adolescent sexual health among teachers-in-training. American Journal of Sexuality Education, 1(3), 25-50.

Daciuk, S. (2015). Sexuality and Disability: A comparison of themes found in the sex and disability literature. MC Thesis, City University, Seattle.

Eisenberg, M.E., Madsen, N., Oliphant, J.A., Sieving, R.E., \& Resnick, M. (2010). Am I qualified? How do I Know? A Qualitative Study of Sexuality Educators' Training Experiences. American Journal of Health Education, 41(6), 337-344.

Fisher, T., \& Hall, R.G. (1988). A Scale for the Comparison of the Sexual Attitudes of Adolescents and their Parents. The Journal of Sex Research. 24(1), 90-100.

Foley, R.M. (2008). Special Educators' Competencies and Preparation for the Delivery of Sex Education. Special Services in the Schools, 10(1), 95-112.
Gerchenovitch, Y., Rusu, A.S. (2018). Components of Sexual Health Programs for SE Students and Pre-service Teachers: A Systematic Literature Review. The European Proceedings of Social \& Behavioural Sciences, XLI, 449-459.

Goldman, J.D., \& Coleman, S.J. (2013). Primary school puberty/sexuality education: Student-teachers' past learning, present professional education, and intention to teach these subjects. Sex Education, 13(3), 276-290.

Haberland, N., Rogow, D. (2015). Sexuality Education: Emerging Trends in Evidence and Practice. Journal of Adolescent Health, 56(1), 15-21.

Howard-Barr, E.M., Rienzo, B.A., Pigg. R.M. Jr., \& James, D. (2005). Teacher beliefs, professional preparation, and practices regarding exceptional students and sexuality education. Journal of School Health, 75, 99-104.

Iyer, P., \& Aggleton, P. (2013). Sex education should be taught, fine...but we make sure they control themselves': teachers' beliefs and attitudes towards young people's sexual and reproductive health in a Ugandan secondary school. Sex Education, 13(1), 1-14.

Klein, N.A., \& Breck, S.E. (2010). "I Wish I Had Known the Truth Sooner": Middle School Teacher Candidates' Sexuality Education Experiences. RMLE Online, 33(6), 1-10.

Lapidot-Berman, J., \& Firstater, E. (2018). Sex Education Why Bother? The Contribution of a Sex Education Course in a Multicultural College for Student Teachers. Journal of Advances in Education Research, 3(1), 47-58.

Leung, H., Shek, D.T.L., Leung, E., \& Shek, E.Y.W. (2019). Development of Contextually-relevant Sexuality Education: Lessons from a Comprehensive Review of Adolescent Sexuality Education Across Cultures. International Journal of Environmental Research and Public Health, 16, 62.

Lewin, K. (1951). Field theory in social science. New York: Harper.

Manor-Binyamini, I., Schreiber-Divon M., \& Stein, R. (2013). Sexual education for students with mental retardation: A practical model for teachers. In S.L. Ferrara (Ed.) $S E$ : Standards, teaching practices, and parent expectations (pp. 89-104). New York: Nova.

May, D.C., Kundert, D.K., (1996). Are special educators prepared to meet the sex education needs of their students? A progress report. The Journal of SE, 29(4), 433-441.

Mckay, A., Barrett, M. (1999) Pre-service sexual health education training of elementary, secondary, and physical health education teachers in Canadian faculties of education. The Canadian Journal of Human Sexuality, 8(2), 91-101.

Owens, T. (2014). Supporting Disabled People with Their Sexual Lives: A Clear Guide for Health and Social Care Professionals. London: Jessica Kingsley Publishers.

Parchomiuk, M. (2013). Model of Intellectual Disability and the Relationship of Attitudes Towards the Sexuality of Persons with an Intellectual Disability. Sexuality and Disability, 31(2), 125-139.

Peltzer, K., Promtussananon, S. (2003). HIV/AIDS education in South Africa: Teacher knowledge about HIV/AIDS: Teacher attitude about and control of HIV/AIDS education. Social Behavior and Personality, 31, 349-356.

Porat, O. (2009). Reuth Open Door. IFPA (Israel Family Planning Association, Questionnaire: Attitudes about Sexuality for People with Disabilities. (in Hebrew).

Prochaska, J.O., Velicer, W.F., Rossi, J.S., Goldstein, M.G., Marcus, B.H., Rakowski, W., ... \& Rossi, S.R. (1994). Stages 
of change and decisional balance for 12 problem behaviors. Health Psychology, 13(1), 39-46.

Rosenstock, I.M. (1991). The Health Belief Model: Explaining health behaviour through expectancies. In K. Glanz, F.M. Lewis, \& B.K. Rimer (Eds.). Health behavior and health education (pp. 39-62). San Francisco: Jossey-Bass.

Sheridan, C. (2016) Staff and Public Attitudes towards Sexuality, Marriage and Parenting regarding People with Intellectual Disabilities. Higher Diploma.

Swango-Wilson, A. (2010). Systems theory and the development of sexual identity for individuals with intellectual/ developmental disability. Sexuality and Disability, 28(3), 157-164.

Taylor, D., Bury, M., Campling, N., Carter, S. Garfield, S. Newbould, J., \& Rennie, T. (2007) A Review of use of the Health Belief Model (HBM), the Theory of Reasoned Action (TRA), the Theory of Planned Behaviour (TPB), and the Trans-Theoretical Model (TTM) to study and predict health related behaviour change. The National Institute for Health and Clinical Excellence. University of London: The School of Pharmacy, London.

Thorpe, S., Oakes L. (2019). Sexual Health Training Needs for Postsecondary Education Program Staff: A Mixed Methods Study. Journal of Inclusive Postsecondary Education, 1(2). Available at: https://doi.org/10.13021/jipe.2019.2411 (accessed at 24.112019).

Travers, J., Tincani, M., Whitby, P.S., \& Boutot, E.A. (2014). Alignment of sexuality education with self-determination for people with significant disabilities: a review of research and future directions. Education and Training in Autism and Developmental disabilities, 232-247.

Treacy, A.C., Taylor, S.S., \& Abernathy, T.V. (2018). SHE for Individuals with Disabilities: A Call to Action. American Journal of Sexuality Education, 13(1), 65-93.

Wilkenfeld, B.F., Ballan, M.S. (2011). Educators' attitudes and beliefs towards the sexuality of individuals with developmental disabilities. Sexuality and Disability, 29(4), 351-361. 